\title{
Formulation and Evaluation of Herbal Shampoo: A Comparative Study By DoE/QbD Approach
}

\author{
Nikita R.Nikam*, Yogita M. Kolekar
}

Adarsh College of Pharmacy, Vita, Tal- Khanapur, Dist- Sangli, Maharashtra,

Department of Statistics, Shivaji University, Kolhapur, Maharashtra

Corresponding Author: E-mail: nikitanikam10@gmail.com, kolekaryogita13@gmail.com 


\begin{abstract}
:
Some ancient medications were used to make the hair care herbal shampoo powder. Organoglytics, powder characteristics, foam test, and physical evaluation were performed on Tulsi, Shikakai, Heena, Bahera, Amla, Neem, and Brahmi. Existing inspections will assist set standards and assessment criteria, which will undoubtedly aid to standardise the quality and purity of these herbal powder shampoos, due to the selection of drugs once the drugs are used together or jointly. We optimise the formula with the help of the Design of Experiments as per the Quality by Design approach.

This paper illustrates broad theoretical as well as practical view of advanced screening design. In addition to the statistical concept's regression analysis, parato chart, residual diagnosis, main effect plot, interaction effect plot, design space and multiple response prediction.
\end{abstract}

Keywords: Herbal shampoo; Foam test; Design of Experiments; QbD; Statistical analysis. 


\section{Introduction:}

Hair is an essential component of human attractiveness. Plants have been used for cleanliness, cosmetics, and management since antiquity. Synthetic agents have contributed significantly over time, but people are now aware of their detrimental effects on the skin and eyes.

Herbal products, which are affordable and have little negative effects, have drawn people to these areas. Not just for cleaning the hair, but also for lightening it and keeping it under control and coordinated ${ }^{1}$.

You must build your product and procedures to assure predefined product quality, safety, and efficacy in order to attain Quality by Design. This necessitates an understanding of how the composition and methods of your product affect quality, safety, and efficacy. ${ }^{13}$

Shampoos are of the following types: ${ }^{12}$

$>\quad$ Powder Shampoo

$>\quad$ Liquid Shampoo

$>\quad$ Lotion Shampoo

$>\quad$ Cream Shampoo

$>\quad$ Jelly Shampoo

$>\quad$ Aerosol Shampoo

$>\quad$ Specialized Shampoo

-Conditioning Shampoo

-Anti-dandruff Shampoo

-Baby Shampoo

-Two Layer Shampoo

Ideal Characteristics of Shampoo:

1. Should effectively and completely remove the dust, excessive sebum.

2. Should effectively wash hair.

3 . The shampoo should be easily removed by rinsing with water.

4. Should impart a pleasant fragrance to the hair.

5. Should not have any side effects or cause irritation to skin or eye. ${ }^{2}$

Composition of Shampoo:

1. Surfactant

2. Antidandruff agent

3. Conditioning agent

4. Pearlescent agent

5. Sequestrants

6. Thickening agent

7. Colures, perfumes and preservative ${ }^{2}$

Materials and Methods:

Selected herbal drugs in dried form were purchased from the authenticated agencies. Herbs along with their part used in shampoo and quantity taken are tabulated in Table $1 .^{3-5}$

Preparation of the herbal shampoo powder:

All the required powders for shampoo preparation were weighed individually, passed through sieve no.120 mesh and mixed in ascending order by weight with continuous trituration ${ }^{6}$. Total two batches of each preparation were prepared labeled and kept in closed container for further studies.

Table 1: Herbal drugs used in powder shampoo formulation

\begin{tabular}{|c|c|c|c|}
\hline Constituents & Biological source/family & Uses & $\begin{array}{c}\text { Quantity Sample } \\
\text { (\%) }\end{array}$ \\
\hline $\begin{array}{c}\text { Harada } \\
\text { (Myrobalan) }\end{array}$ & $\begin{array}{c}\text { Dried ripe fruits of } \\
\text { Terminalia chebula } \\
\text { (Combretaceae) }\end{array}$ & $\begin{array}{c}\text { Hair Growth } \\
\text { Promoter }\end{array}$ & 6.25 \\
\hline Bahera & $\begin{array}{c}\text { Dried ripe fruits } \\
\text { Terminalia bellirica } \\
\text { (Combretaceae) }\end{array}$ & $\begin{array}{c}\text { Provides nutrition to } \\
\text { growing hair }\end{array}$ & 9.37 \\
\hline Amla & $\begin{array}{c}\text { Dried ripe fruits of } \\
\text { Embelica officinalis } \\
\text { (Euphorbiaceae) }\end{array}$ & Hair growth promoter & 7.5 \\
\hline
\end{tabular}




\begin{tabular}{|c|c|c|c|}
\hline Neem & $\begin{array}{c}\text { Dried leaves of } \\
\text { Azadirachta indica } \\
\text { (Miliaceae) }\end{array}$ & $\begin{array}{l}\text { Antiseptic } \\
\text { antibacterial }\end{array}$ & 3.12 \\
\hline Tulsi & $\begin{array}{c}\text { Dried leaves of } \\
\text { Ocimumsantum } \\
\text { (Labiateal) }\end{array}$ & antibacterial & 0.6 \\
\hline Shikakai & $\begin{array}{l}\text { Dried seeds of Acacia } \\
\text { rugate (Leguminesue) }\end{array}$ & Foam base & 10 \\
\hline Hibiscus & $\begin{array}{c}\text { Dried leaves of Hibisucus } \\
\text { rosea (Malvaceae) }\end{array}$ & Conditioner & 10 \\
\hline Brahmi & $\begin{array}{l}\text { Dried leaves of centlla } \\
\text { asiatica (Umbelliferae) }\end{array}$ & $\begin{array}{c}\text { Support Health of } \\
\text { Hair }\end{array}$ & 3.75 \\
\hline $\begin{array}{l}\text { Aloevera } \\
\text { Powder }\end{array}$ & $\begin{array}{c}\text { Dried leaves of Aloe } \\
\text { barbadensis miller } \\
\text { (Asphodelaceae) }\end{array}$ & $\begin{array}{c}\text { Moisturizer } \\
\text { And Conditioner }\end{array}$ & 9.37 \\
\hline Bhringraj & $\begin{array}{l}\text { Dried leaves of Eclipta } \\
\text { Alba (Asteraceae) }\end{array}$ & Hair tonic & 6.25 \\
\hline
\end{tabular}

\section{Initial risk assessment}

We believe that shikakai, hibiscus, and aloe vera powder are three important material properties for herbal shampoo, with related CQAs foaming volume and moisture content, based on our research and scientific understanding. Perform DoE experiments as per the QbD strategy for the sake of confidence. Through design space, learn about herbal shampoo.

\subsection{Objective of DoE}

Herbal shampoo contains 100 grammes to optimise CMAs. The Design of Experiments is finalised based on brainstorming and risk assessment criteria (with their levels) and their replies (DoE). DoE was utilised to characterise (advanced screen) the formula parameters of herbal shampoo $100 \mathrm{gm}$. The table below shows the critical formula factors, also known as formula parameters, as well as the levels and responses, or dependent variables.

Table 2: Critical Formula Parameters and Responses for Design of Experiment.

\begin{tabular}{|c|c|c|c|c|}
\hline \multicolumn{2}{|c|}{$\begin{array}{c}\text { Factors: Critical Formula Parameters } \\
\text { (Independent Variables) }\end{array}$} & Low (-1) & Optimum (0) & High (+1) \\
\hline $\boldsymbol{A}$ & Shikakai & $5.0 \mathrm{gm}$ & $10.0 \mathrm{gm}$ & $15.0 \mathrm{gm}$ \\
\hline $\boldsymbol{B}$ & Hibiscus & $5.0 \mathrm{gm}$ & $10.0 \mathrm{gm}$ & $15.0 \mathrm{gm}$ \\
\hline $\boldsymbol{C}$ & Aloe Vera Powder & $9.65 \mathrm{gm}$ & Goal & Acceptable Ranges \\
\hline \multicolumn{2}{|r|}{$\begin{array}{c}\text { Responses: Critical Quality Attributes } \\
\text { (Dependent Variables) }\end{array}$} & Maximize & NLT $170 \mathrm{ml}$ \\
\hline $\boldsymbol{Y}_{\boldsymbol{I}}$ & \multicolumn{2}{|r|}{ Foaming Volume } & Target & $3.0 \%-4.5 \%$ \\
\hline $\boldsymbol{Y}_{\mathbf{2}}$ & \multicolumn{2}{|r|}{ Moisture Content } & $\mathrm{gm}$ \\
\hline
\end{tabular}

\subsection{Selection of Experimental Design \& Design matrix}

2.0 Full Factorial Experimental Design was used for improved screening of crucial formula parameters of herbal shampoo $100 \mathrm{gm}$. With all potential permutation combination studies, the use of a full factorial 
design will aid in understanding individual as well as interaction effects at low, medium, and high levels (considering centre points).

3.0 The design matrix looks like this: $\mathrm{Lf}=23=8$ base trials with two centre points. As part of the full factorial design, a total of ten trial sets were planned. The design matrix, as well as the results of the tests, are presented in the next section.

\subsection{Experimental results of the DoE study for herbal shampoo $100 \mathrm{gm}$}

Minitab 18 was used to create a design matrix based on the objective. Experiments for herbal shampoo 100 gm were conducted and assessed for their impact on CQAs (i.e., reactions). Foaming volume and moisture content responses to A-Shikakai, B-Hibiscus, and C-Aloe Vera Powder key material attributes (CMAs).

The following is a list of the findings of the experiments that were conducted:

Table 3: Experimental design table as per DoE full factorial design.

\begin{tabular}{|c|c|c|c|c|c|}
\hline \multirow{2}{*}{ Batch No. } & \multicolumn{3}{|c|}{$\begin{array}{c}\text { Factors: Critical Formula } \\
\text { Parameters }\end{array}$} & \multicolumn{2}{c|}{ Responses: Critical Quality Attributes } \\
\cline { 2 - 6 } & A & B & C & $\begin{array}{c}\text { Quantitative } \\
\text { (m) })\end{array}$ & $\begin{array}{c}\text { Moisture Content } \\
(\%)\end{array}$ \\
\hline 1 & & & & 135.0 & 3.4 \\
\hline 2 & 10.0 & 10.0 & 9.3 & 145.0 & 3.78 \\
\hline 3 & 10.0 & 10.0 & 9.3 & 143.0 & 3.72 \\
\hline 4 & 15.0 & 5.0 & 13.95 & 155.0 & 4.0 \\
\hline 5 & 15.0 & 5.0 & 4.65 & 151.0 & 3.2 \\
\hline 6 & 5.0 & 15.0 & 4.65 & 136.0 & 4.0 \\
\hline 7 & 5.0 & 5.0 & 13.95 & 138.0 & 3.28 \\
\hline 8 & 15.0 & 15.0 & 4.65 & 160.0 & 4.2 \\
\hline 9 & 5.0 & 15.0 & 13.95 & 138.0 & 4.1 \\
\hline 10 & 15.0 & 15.0 & 13.95 & 158.0 & $3.0 \%-4.5 \%$ \\
\hline
\end{tabular}

Abbreviations:

A - Shikakai, B - Hibiscus and C-Aloe Vera Powder

Color code:Low, Medium and High

Statistical Analysis and drawing inference: ${ }^{13}$

Pictorial View -

1. Foaming Volume (ml): 


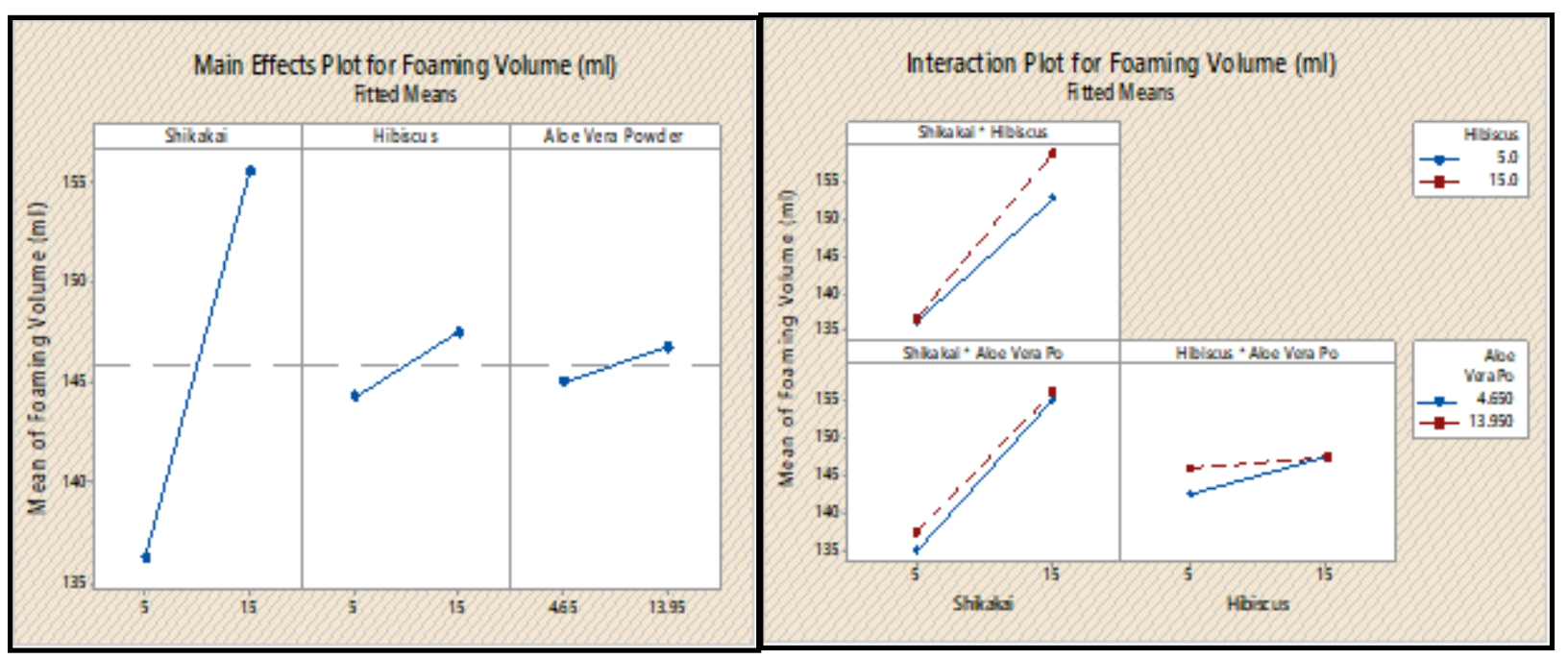

As quantity of A-shikakai increase, foaming volume in $\mathrm{ml}$ also increase. While there is no significant impact of Bhibiscus and $\mathrm{C}$-aloe vera powder on foaming volume. There is no significant interaction between $\mathrm{AB}-$ shikakai*hibiscus, AC-shikakai*aloe vera powder and BC-hibiscus*aloe vera powder



- Residual diagnosis indicates that, residuals are randomly distributed and no bias included during trial execution, follow approximate normality, having constant variance.

- From parato chart observed that, only main effect A-shikakai has significant effect on foaming volume $(\mathrm{ml})$. 


\section{Moisture Content (\%):}

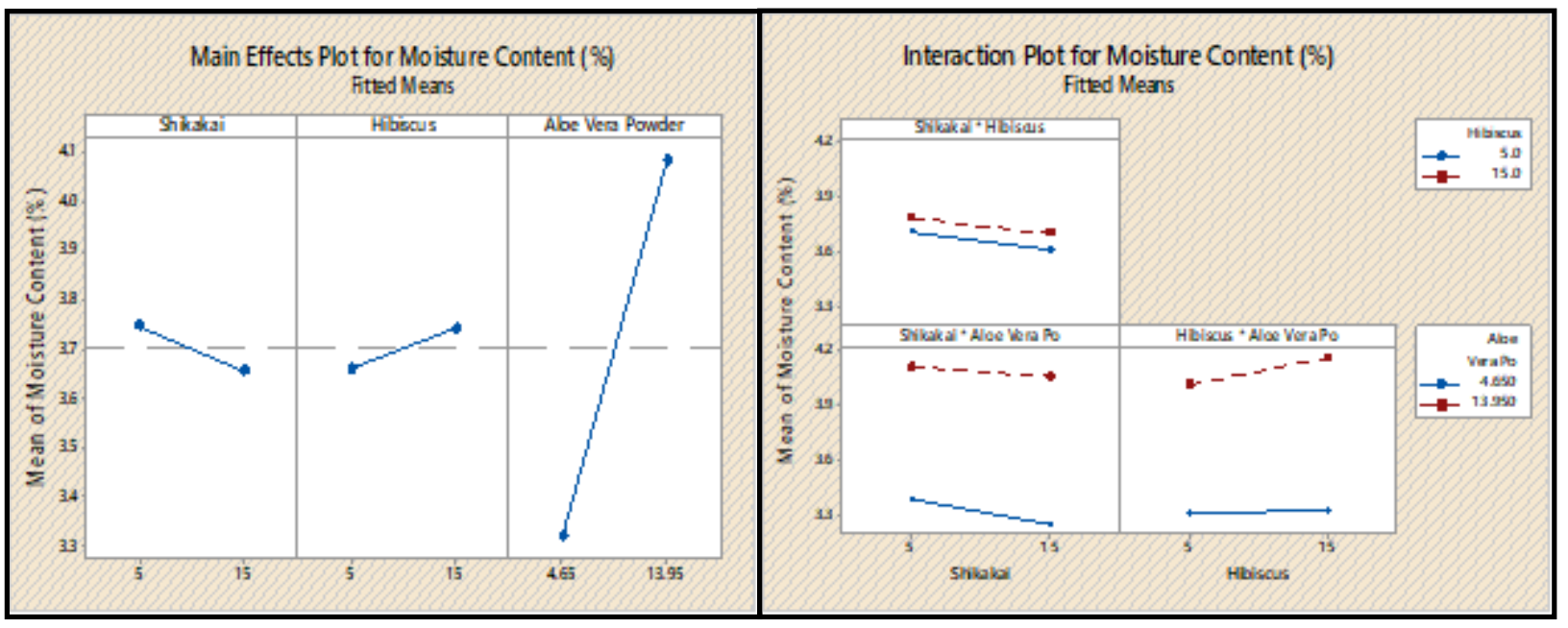

As the amount of $\mathrm{C}$-aloe vera powder increases, so does the percent moisture content. A-shikakai and B-hibiscus had no effect on the percent moisture content of the plant. AB-shikakai*hibiscus, AC-shikakai*aloe vera powder, and BC-hibiscus*aloe vera powder have no significant interactions.
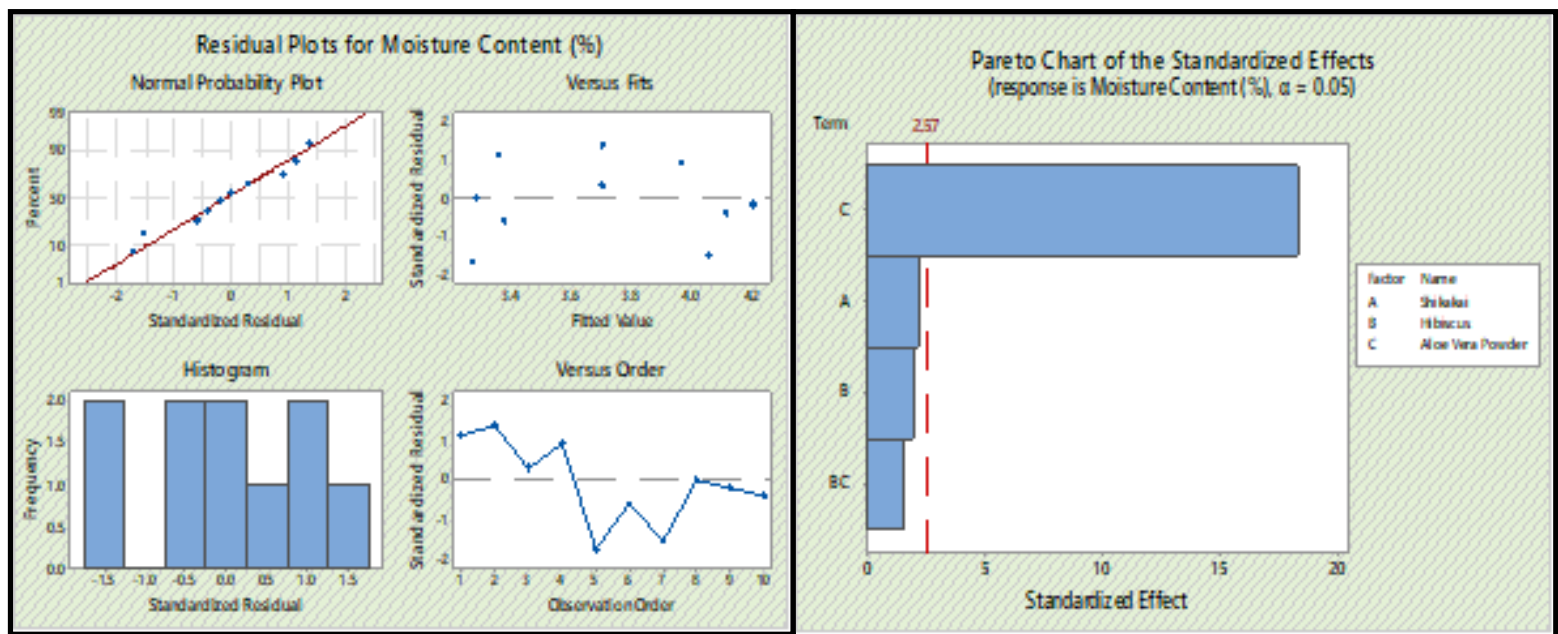

- Residual diagnosis indicates that, residuals are randomly distributed and no bias included during trial execution, follow approximate normality, having constant variance.

- From parato chart observed that, only main effect $\mathrm{C}$-aloe vera powder has significant effect on \%moisture content.

\subsection{Summary for significant/Non-significant factors (Formula Screening)}

After analyzing the data from experiments, the significant/ Non-significant factors can be summarized in below table as - 
Table 4: Summary for significant/Non-significant factors

\begin{tabular}{|c|c|c|}
\hline \multirow{2}{*}{$\begin{array}{c}\text { Factors: Critical Formula } \\
\text { Parameters }\end{array}$} & \multicolumn{2}{|c|}{ Responses: Critical Quality Attributes } \\
\cline { 2 - 3 } & \multicolumn{2}{|c|}{ Quantitative Response } \\
\cline { 2 - 3 } & $\begin{array}{c}\text { Foaming Volume } \\
(\mathbf{m l})\end{array}$ & Moisture Content (\%) \\
\hline $\boldsymbol{A}$ - Shikakai & Significant & Non-significant \\
\hline $\boldsymbol{B}$ - Hibiscus & Non-significant & Non-significant \\
\hline $\boldsymbol{C}$ - Aloe Vera Powder & Non-significant & Significant \\
\hline $\boldsymbol{A B}$ - Interaction & Non-significant & Non-significant \\
\hline $\boldsymbol{A C}$ - Interaction & Non-significant & Non-significant \\
\hline $\boldsymbol{B C}$ - Interaction & Non-significant & Non-significant \\
\hline $\boldsymbol{A B C}$ - Interaction & Non-significant & Non-significant \\
\hline Curvature & Non-significant & Non-significant \\
\hline Model & Significant & Significant \\
\hline
\end{tabular}

\subsection{Overlaid Contour Plot ${ }^{16} 17$}

Using Minitab18 statistical software, an overlaid contour plot was created based on the target criteria for each CQA as listed in table 1.

Use an Overlaid Contour Plot to visually highlight an area where one or more response variables' estimated means are within an acceptable range. Find the white area, which is the viable zone, on the superimposed contour map. Given the holding values of any additional variables, the feasible region is the area produced by the two continuous variables, such that the fitted values for each response are between their respective outlines.

The white area in the plot represents the combination of shikakai and aloe vera powder levels that produce appropriate fitted values for both response variables, Foaming Volume ( $\mathrm{ml}$ ) and Moisture Content (percent ). As a result, any shikakai and aloe vera powder variable values that fall within this range should yield a product with acceptable mean responses.

All two responses, foaming volume $(\mathrm{ml})$ and moisture content (percent), for the herbal shampoo data are well within specification. As a result, the only viable zone is white. 


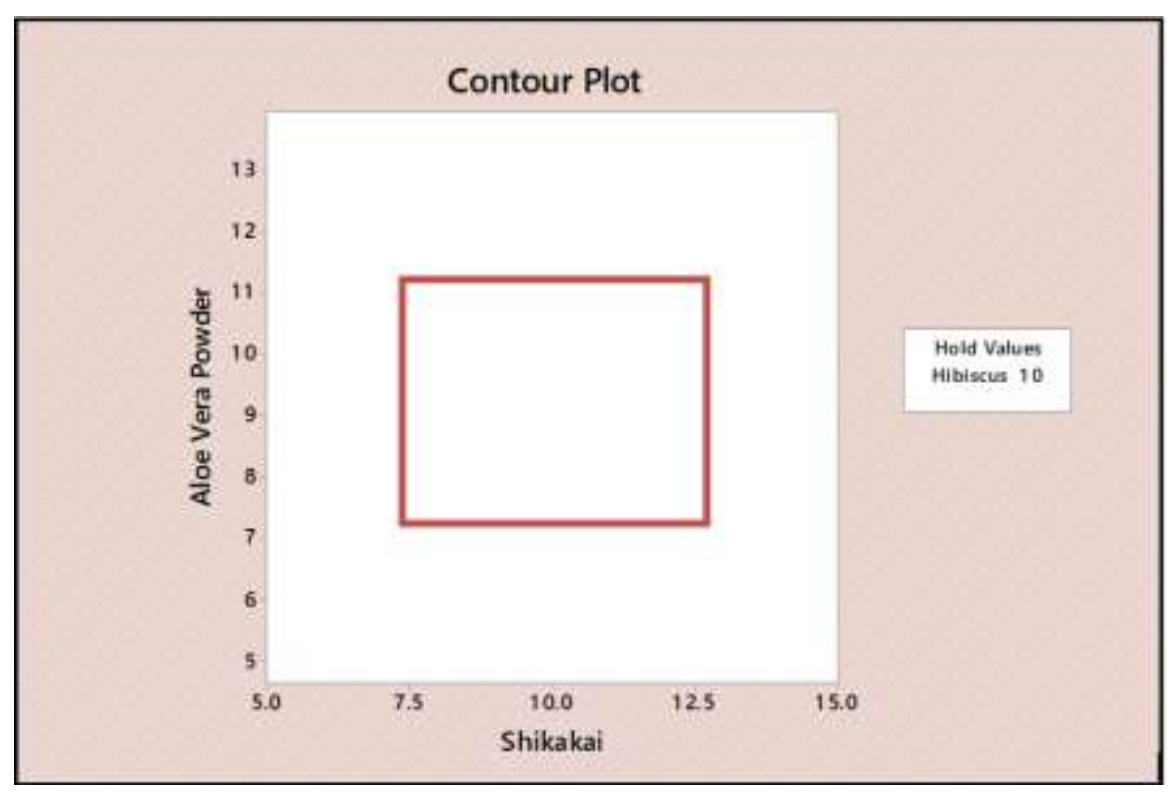

The un-shaded area, i.e., control space (which is summarised in the following section), is derived for targeted specification to accomplish QTPP, according to the above superimposed contour plot.

\subsection{Response optimization plot (Prediction from Minitab 18)}

Based on targeted value for each CQAs (as defined in table 1), response optimization plot is generated from Minitab 18 and given below.

Table 5: Response optimization

\begin{tabular}{|c|c|c|}
\hline \multirow{2}{*}{ Factors: Critical Formula Parameters } & \multicolumn{2}{|c|}{ Responses: Critical Quality Attributes } \\
\cline { 2 - 3 } & \multicolumn{2}{|c|}{ Quantitative Response } \\
\cline { 2 - 3 } & $\begin{array}{c}\text { Foaming Volume } \\
(\mathbf{m l})\end{array}$ & $\begin{array}{c}\text { Moisture Content } \\
(\%)\end{array}$ \\
\hline $\begin{array}{c}\text { A - Shikakai (10.0 gm) } \\
\text { B - Hibiscus (10.0 gm) } \\
\text { C -Aloe Vera Powder (9.30 gm) }\end{array}$ & 145.90 & \\
(Prediction from Minitab 18) & & 3.70 \\
\hline Validation Batch & 144.50 & 3.72 \\
\hline
\end{tabular}




\subsection{Recommendation}

For the further future batches, recommendations are summarized as below -

Table 6: Recommendation

\begin{tabular}{|c|c|c|c|}
\hline $\begin{array}{c}\text { Factors: Critical Formula } \\
\text { Parameters }\end{array}$ & Range Studied & Design Space & Control Space \\
\hline Shikakai (A) & $5.0 \mathrm{gm}-15.0 \mathrm{gm}$ & $7.5 \mathrm{gm}-12.5 \mathrm{gm}$ & $10.0 \mathrm{gm}$ \\
\hline Hibiscus (B) & $5.0 \mathrm{gm}-15.0 \mathrm{gm}$ & $7.0 \mathrm{gm}-13.0 \mathrm{gm}$ & $10.0 \mathrm{gm}$ \\
\hline Aloe Vera Powder $(\mathbf{C})$ & $4.65 \mathrm{gm}-13.95 \mathrm{gm}$ & $7.5 \mathrm{gm}-11.5 \mathrm{gm}$ & $9.30 \mathrm{gm}$ \\
\hline
\end{tabular}

\section{Evaluation of Herbal Shampoo Powder:}

\section{A. Organoleptic evaluation:}

Color, taste, smell, and texture were all evaluated as part of the organoleptic evaluation process. Vision and tactile sensitivity were used to evaluate colour and composition, respectively. For the assessment of taste and scents, a team of five people sensitive to taste and odours was formed, and a random sample was taken. ${ }^{1}$

\section{B. General powder characteristic:}

Common characteristics of the powder include the evaluation of parameters that will affect external properties (such as flow properties, appearance, packaging criteria, etc.).

a. Particle size is a variable that influences spreading, granularity, and other features. The particle size was assessed by mechanical churning for 10 minutes using the sieve method with a standard I.P. Sieve.

b. Angle of repose has an impact on the powder's flow qualities The glass funnel method was used to determine this. Between the grid paper and the powder's bottom, a $2 \mathrm{~cm}$ gap is created. The glass funnel played a role in this. The upper part of the battery keeps flowing until it reaches the funnel's bottom ${ }^{11}$.

c. Bulk density: For product packaging, this is a valuable advantage. To determine bulk density, weighted volumes of powder were added to a $100 \mathrm{ml}$ graduated cylinder. The cylinder was placed on an apparent density instrument, and the apparent density was determined ${ }^{7-8}$.

d. Tapped density is the apparent density of a powder sample acquired after mechanical tapping of a container. The graduated cylinder or vessel is mechanically tapped for 1 minute after observing the volume or mass of the beginning powder, and volume or mass readings are taken until the next change in volume or mass. This is measured in $\mathrm{g} / \mathrm{cm} 3$ (grammes per cubic centimetre) ${ }^{6}$.

\section{C.Physicochemical Evaluation:}

a. pH: At room temperature, $25^{\circ} \mathrm{C}$, the $\mathrm{pH}$ of a $10 \%$ shampoo solution in distilled water was determined. A digital $\mathrm{pH}$ metre was used to determine the $\mathrm{pH}$.

b. Washability: The ease and extent of washing with water were personally examined after the formulations were applied to the skin.

c. Solubility: The solute's potential is dissolved in its solubility. One gramme of powder is precisely weighed and added to a beaker with $100 \mathrm{~mL}$ of water. To improve solubility, it was thoroughly shook and heated. The resulting residue is weighed and recorded after cooling and sifting them.

d. Ash value: A silicon plate containing about 2 grammes of powder medication was previously burned and weighed. The heat was gradually increased until the temperature reached a red colour. The ash is cooled and weighed after it has completely burned ${ }^{10-11}$.

e. Acid insoluble ash: Boiling above acquired ash with $25 \mathrm{ml}$ dil. $\mathrm{HCl}$ for 5 minutes yielded acid insoluble ash, which was collected in a gooch crucible, cleaned with hot water, ignited, and weighed ${ }^{10-11}$. 
f. Dirt Dispersion: Ten millilitres of water are mixed with two drops of one percent shampoo powder in a big test container. The test piece was closed and moved ten times after a drop of ink from China was applied. The ink in the foam wasn't light, medium, or thick at all ${ }^{9}$.

g. Moisture Content Determination: Each $10 \mathrm{gm}$ of herbal shampoo powder is evaporated and baked at $105^{\circ} \mathrm{C}$ in a hot air oven. Dry for another 30 minutes, then lose weight steadily. Each sample's moisture content was calculated ${ }^{9}$.

\section{D.Extractive Values:}

a. Determination of alcohol soluble extractive: Each $5 \mathrm{gm}$ air-dried herbal powder shampoo is wet in a closed flask for 24 hours with $100 \mathrm{ml}$ of a prescribed volume of alcohol. To avoid damaging the solvent by filtering, $25 \mathrm{~mL}$ of the filtrate was evaporated to dryness in a shallow dish flat star and kept dry at $105^{\circ} \mathrm{C}$. In comparison to the air-dried medication, the percentage of soluble extract intake in alcohol has been estimated ${ }^{9}$.

b. Determination of water-soluble extractive: To determine soluble alcohol extracts, use chloroform water instead of ethanol as advised. The percentage of extract dissolved in water was calculated for each sample ${ }^{9}$.

c. Foaming Capacity: Foam stability tests with $2 \mathrm{gm}$ of powder and $50 \mathrm{ml}$ water in a graduated cylinder for different time periods were used to calculate the foaming capacity of the test herbal powder shampoos (SNI\& SN-II).

d. Ease of distribution: The ease of distribution was tested by applying $5 \mathrm{ml}$ of the formulation to wet hair and measuring the time it took to complete the dispersion ${ }^{14}$.

e. Ease of rinsing: The time it took to remove the detergent was measured by adding $5 \mathrm{ml}$ of shampoo to the wash water and measuring the time it took to completely eliminate the foaming.

f. Ease of combing (Wet): The ease of combing was determined by running a comb through damp hair and observing how smoothly the comb glided.

g. Ease of Combing (Dry): The ease of combing was tested by running a comb through dry hair and seeing if it glided easily ${ }^{14}$. 
RESULTS: Evaluation results of herbal shampoo powder are tabulated as follow:

A) Organoleptic evaluation:

Table 7: Organoleptic evaluation parameters and results

\begin{tabular}{|c|c|c|}
\hline Sr. No. & $\begin{array}{c}\text { Organoleptic } \\
\text { evaluation }\end{array}$ & Result \\
\hline 1 & Colour & Greenish brown \\
\hline 2 & Odour & Slight pleasant \\
\hline 3 & Taste & Characteristics \\
\hline 4 & Texture & Fine smooth \\
\hline
\end{tabular}

B) General powder characteristics:

Table 8: General powder characteristics and results

\begin{tabular}{|c|c|c|}
\hline Sr. No. & $\begin{array}{c}\text { General powder } \\
\text { characteristic }\end{array}$ & Result \\
\hline 1 & Particle size & $20-25 \mu \mathrm{m}$ \\
\hline 2 & Angle of repose & 28.36 \\
\hline 3 & Bulk density & $0.40 \mathrm{gm} / \mathrm{ml}$ \\
\hline 4 & Tapped density & $0.48 \mathrm{gm} / \mathrm{ml}$ \\
\hline
\end{tabular}

C) Angle of repose:

Table 9: Calculation for Angle of repose of herbal shampoo

\begin{tabular}{|c|c|c|c|c|c|c|}
\hline Method & $\begin{array}{c}\text { Height of } \\
\text { cone(cm) }\end{array}$ & $\begin{array}{c}\text { Radius of } \\
\operatorname{cone}(\mathbf{c m})\end{array}$ & $\tan \boldsymbol{\theta}=\mathbf{( h / \mathbf { r } )}$ & $\begin{array}{c}\text { Average } \\
\tan \boldsymbol{\theta}\end{array}$ & $\begin{array}{c}\boldsymbol{\theta}=\text { tan-1 } \\
(\mathbf{h} / \mathbf{r})\end{array}$ & $\begin{array}{c}\text { Flow } \\
\text { property }\end{array}$ \\
\hline $\begin{array}{c}\text { Funnel } \\
\text { method }\end{array}$ & 2 & 3.5 & 0.57 & 0.57 & 29.68 & Good \\
\hline
\end{tabular}

D) Bulk density:

Table 10: Bulk density calculation of herbal shampoo

\begin{tabular}{|c|c|c|c|c|}
\hline Sr. No. & $\begin{array}{c}\text { Bulk of volume } \\
(\mathbf{m l})\end{array}$ & $\begin{array}{c}\text { Mass of the Powder } \\
(\mathbf{g})\end{array}$ & $\begin{array}{c}\text { Bulk } \\
\text { density } \\
(\mathbf{g} / \mathbf{m l})\end{array}$ & $\begin{array}{c}\text { Average bulk density } \\
(\mathbf{g} / \mathbf{m l})\end{array}$ \\
\hline 1 & 42 & 20 & 0.47 & \multirow{2}{*}{0.47} \\
\hline 2 & 42 & 20 & 0.47 & \\
\hline 3 & 42 & 20 & 0.47 & \\
\hline
\end{tabular}


E) Tapped density:

Table11: Tapped density calculation of herbal shampoo

\begin{tabular}{|c|c|c|c|c|}
\hline Sr. No. & $\begin{array}{c}\text { Tapped volume } \\
(\mathbf{m l})\end{array}$ & $\begin{array}{c}\text { Mass of the powder } \\
(\mathbf{g})\end{array}$ & $\begin{array}{c}\text { Tapped } \\
\mathbf{d e n s i t y} \\
(\mathbf{g} / \mathbf{m l})\end{array}$ & $\begin{array}{c}\text { Average } \\
\text { tappedDensity } \\
(\mathbf{g} / \mathbf{m l})\end{array}$ \\
\hline 1 & 38 & 20 & 0.52 & \multirow{2}{*}{0.52} \\
\hline 2 & 38 & 20 & 0.52 & \multirow{2}{*}{0.52} \\
\hline 3 & 38 & 20 & 0.52 & \\
\hline
\end{tabular}

F) Foam ability:

Table 12: Foam stability of Shampoo

\begin{tabular}{|c|c|}
\hline $\begin{array}{c}\text { Time } \\
(\mathbf{m i n})\end{array}$ & $\begin{array}{c}\text { Foam Volume } \\
(\mathbf{m l})\end{array}$ \\
\hline 1 & 146 \\
\hline 2 & 142 \\
\hline 3 & 139 \\
\hline 4 & 136 \\
\hline
\end{tabular}

G) Physicochemical evaluation:

Table 13: Physicochemical properties

\begin{tabular}{|c|c|c|}
\hline $\begin{array}{l}\text { Sr. } \\
\text { No. }\end{array}$ & $\begin{array}{l}\text { Physicochemical } \\
\text { evaluation }\end{array}$ & Result \\
\hline 1 & $\mathrm{PH}$ & 5.55 \\
\hline 2 & Washability & Easily washable \\
\hline 3 & Skin / eye irritation & $\begin{array}{c}\text { No harmful effect on } \\
\text { the skin }\end{array}$ \\
\hline 4 & Foaming capacity & $\begin{array}{l}\text { Good foaming } \\
\text { (145) }\end{array}$ \\
\hline \multirow{3}{*}{5} & \multicolumn{2}{|l|}{ Extractive values: } \\
\hline & a) Alcohol soluble & $30.60 \% \mathrm{w} / \mathrm{w}$ \\
\hline & b)water soluble & $25.15 \% \times x / \mathrm{w}$ \\
\hline \multirow{3}{*}{6} & \multicolumn{2}{|l|}{ Ash value: } \\
\hline & a) Total ash value & 4.5 \\
\hline & b) Acid insoluble ash & 2.05 \\
\hline
\end{tabular}




\begin{tabular}{|c|c|c|}
\hline 7 & Dirt dispersion & Light \\
\hline 8 & Moisture content & $3.78 \%$ \\
\hline 9 & Solubility & Soluble \\
\hline 10 & Ease of distribution & Best \\
\hline 11 & Ease of rinsing & Best \\
\hline 12 & Ease of combing (wet) & Best \\
\hline 13 & Ease of combing (dry) & Best \\
\hline
\end{tabular}

\section{Discussion:}

Herbal powders have been prepared using herda, deaf, avala, shikakai, kadunimb, basil, henna and brahmi in different types of crude drugs (Table 1). Several quality control criteria were investigated. All of the parameters yield positive results. When the active elements of these pharmaceuticals are mixed into the shampoo, more stable products with a superior visual appeal are obtained, according to the findings of this study.

The powder formulation's general qualities were found to be satisfactory. As shown in the table, extract values (percent $\mathrm{w} / \mathrm{w}$ ) in organic solvents such as petroleum ether, chloroform benzene, acetone, and methanol were computed. This formulation's moisture content was measured to be 3.7878 percent w/w. The $\mathrm{pH}$ of the mixture was discovered to be between 5 and 6 . (Table 8 ). Table 8 shows the results of the other formulas' evaluations.

\section{Conclusion:}

Design of Experiment investigates which independent variables are responsible for observed changes in the response; construct a model tying the response to the important input variables (CMAs); and use this model for formulation, system improvement, or other decision-making. Herbal medications contribute to the beauty of the worldwide market, health care, hair preparation, and hair preparation in today's world. As a result, we've come to the conclusion that the powdered herbal shampoo recipe decreases swelling, minimises side effects, and promotes conditioning. These are preliminary experiments, however the assessment value provided for the honesty of herbal powder shampoo will be useful. It has been determined that shampoo powder is satisfactory, and that all of the required features are determined by humidity time, foam stability, filth, and cleanliness. This is a more acceptable formulation. Powder shampoo is a dry powder that is applied to the hair. The long store's stability and durability have remained unchanged. A well-designed experiment is vital because the results and conclusions that may be derived from it are heavily influenced by the way the data was collected and evaluated.

\section{Acknowledgment:}

The authors would like to thank Head, Dept of Adarsh College of Pharmacy and Shivaji University for providing necessary research facilities. 


\section{References:}

1. Surupsing M. Vlavi*, Akash D. Patil, Harishchandra M. Yeowle, Vipul H. Jain and Pawar SP, 'Formulation and Evaluation of Herbal Shampoo Powder', International Journal of Pharma AndChemical Research I Volume 3 I Issue 3 I Jul - Sep I 2017,Page no.492-493.

2. Sutar Manisha, Deshmukh Swati, Chavan Manisha, Singh Sonia, 'Preparation and evaluation of polyherbal shampoo powder', International Journal of Pharmacy and Biological sciences 392; 2013: 151-159.

3. Swati Deshmukh, Bindurani Kaushal, Shweta Ghode. Formulations and evaluation of herbal shampoo and comparative studies with herbal marketed shampoo. International Journal of Pharma and Bio Sciences 3(3); 2012: 638-645.

4. Naresh Gorantla, Sai Prasad K, Thima Reddy VT, Ragadeepika J, Hajarabi T, Hindustan Abdul Ahad. Formulation and evaluation of herbal shampoo containing chamomile, rose and orange peel. Pharma Research Library: International Journal of Medicine and Pharmaceutical Research 1(2); 2013: 192-197.

5. Ashok Kumar, Rakesh Roshan Mali. Evaluation of prepared shampoo formulations and to compare formulated shampoo with marketed shampoos. International Journal of Pharmaceutical sciences Review and Research 3(1); 2010: 120-127.

6. Sutar Manisha*, Deshmukh Swati, Chavan Manisha, Singh Sonia,'Preparation AND EVALUATION OF POLYHERBAL SHAMPOO POWDER', International Journal of Pharmacy and Biological Sciences (eISSN: 2230-7605), IJPBS |Volume 3| Issue 2 |APR-JUN |2013|151-159.

7. Martin Alfred "Physical pharmacy" 4th edition Lea \&febigen Philadelphia London 431-432, (1993).

8. Subrahmanyam CVS "Text book of physical pharmaceutics" Vallabh prakashan Second edition, 221-224, (2000).

9. Geeta Deswal*, Priyanka Kriplani, 'Formulation and Evaluation of Polyherbal Powder Shampoo', Pharma Research Bulletin / Deswal et al., 2018; 1(1): 20-24

10. Kokate C.K., 'Practical phramacognosy”, Vallabh Prakashan, New Delhi, Forth edition, 123, (1994).

11. "The Pharmacopeia of India “, New Delhi, 947, (1996).

12. Mithal B.M.\&Saha R.N. "A Handbook of Cosmetic" Vallabh Prakashan, New Delhi, First edition, 110$112,(2002)$.

13. Yogita M. Kolekar. "Understanding of DoE and its advantages in Pharmaceutical development as per QbD Approach". Asian J. Pharm. Tech. 2019; 9 (4):271-275

14. Sharma P.P, "Cosmetics Formulation, Manufacturing and Quality Control", Vandan publications, New Delhi, 3, (1998).

15. Rhea Jacob, Sakthivel, K. M., Kannan, N. and *Guruvayoorappan, C.,'FORMULATION OF COST EFFECTIVE HERBAL SHAMPOO POWDER: A COMPARATIVE STUDY WITH MARKET SHAMPOOS', International Journal of Current Research Vol. 7, Issue, 02, pp.12645-12649, February, 2015.

16. Guidance for Industry: Q8 (R2) Pharmaceutical Development

17. Guidance for Industry: Q9 Quality Risk Management and Q10 Pharmaceutical Quality System 